Proceedings of XIX International Scientific Conference "New Technologies and Achievements in Metallurgy, Material Engineering, Production Engineering and Physics", Częstochowa, Poland, June 7-8, 2018

\title{
Mössbauer Spectroscopy Study in Characterization of Steel Production Dusts
}

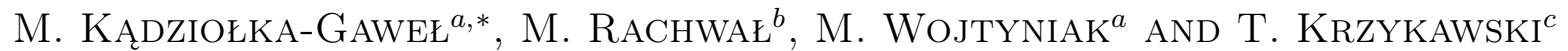 \\ ${ }^{a}$ Institute of Physics, University of Silesia in Katowice, 75 Pułku Piechoty 1a, 41-500 Chorzów, Poland \\ ${ }^{b}$ Institute of Environmental Engineering, Polish Academy of Sciences, \\ M. Skłodowskiej-Curie 34, 41-819 Zabrze, Poland \\ ${ }^{c}$ Faculty of Earth Sciences, University of Silesia in Katowice, Będzińska 60, 41-200 Sosnowiec, Poland
}

\begin{abstract}
Steel production involves processes and alloys based on iron. Metallurgy is one of the most energy-intensive branches of industry and it also generates a lot of damage. The aim of the research was to recognize magnetic properties, mineral composition, and phase content of dusts from a de-dusting station, steel mill, sinter strand and filter press located in a steel metallurgical foundry in Upper Silesia, the most urbanized, industrialized and also the most polluted region of Poland. The following methods were applied: X-ray fluorescence, X-ray diffraction and the Mössbauer spectroscopy measurements.
\end{abstract}

DOI: $10.12693 /$ APhysPolA.135.122

PACS/topics: 33.45.+x, 82.80.Ej, 89.60.Ec, 91.62.Rt

\section{Introduction}

Steel is an alloy of iron, carbon and other elements. The carbon content in the steel is between $0.002 \%$ and $2.1 \%$ of its weight, depending on the grade. Other alloying elements commonly used are $\mathrm{Mn}, \mathrm{Si}, \mathrm{Cr}, \mathrm{Mo}, \mathrm{B}$, $\mathrm{Ti}, \mathrm{V}, \mathrm{Nb}$ [1]. For most of the last decade, global crude steel production has been growing. Steel manufacturing involves processes and alloys based on iron. It requires a large volume of raw materials, of which only a fraction ends up in the final products [2-4]. The remaining by-products include slag, sludge and dust, which are potentially hazardous materials that need to be disposed of in an environmentally responsible way. Another option for dealing with these by-products is recycling. The dusts and wastes produced vary in terms of their chemical and mineral composition caused by raw materials used for steel production, a process which involves a combination of primary resources (iron bearing ores), metal scraps and metallurgical wastes. There is a general worldwide trend for evaluation of technologies which re-use the metallurgical wastes and apply recycling routes as the source of furnace charge. Therefore, the determination of physical and chemical properties of the dusts arisen during the metallurgical process, mainly their phase composition, is the subject of many studies of applied character.

The aim of the research was to recognize magnetic properties, mineral composition and phase content of six samples of dust from steelworks (sample 1), dust from de-dusting station (sample 2), dust from electrofilter precipitator (samples 3 and 4) and iron-bearing mud from

\footnotetext{
* corresponding author; e-mail: mariola.kadziolka-gawel@us.edu.pl
}

filter press (samples 5 and 6). These samples came from a steel metallurgical foundry in Upper Silesia, the most urbanized, industrialized and also the most polluted region of Poland. The following methods were applied: $\mathrm{X}$-ray fluorescence (XRF) and X-ray diffraction (XRD) measurements. In practice, each particular type of dust is unique, which requires application of many different research techniques. Especially, in the case where the dust is rich in the iron bearing phases, the application of routine analytical methods does not always lead to unambiguous results. Therefore, these results were correlated with the spectroscopic data, which was obtained by the Mössbauer spectroscopy.

\section{Experimental procedure}

The chemical composition was determined using X-ray fluorescence (XRF) from ZSX Primus II Rigaku spectrometer. The spectrometer, equipped with the $4 \mathrm{~kW}, 60 \mathrm{kV}$ $\mathrm{Rh}$ anode and wavelength dispersion detection system, enabled the analysis of the elements from Be to U. No external standards were necessary, only the internal standards coupled with the fundamental parameters method (theoretical relationship between measured X-ray intensities and the concentrations of elements in the sample) were implemented.

The samples were examined by X-ray powder diffraction (XRD) using $\mathrm{Cu} K_{\alpha_{1}}$ (from graphite monochromator) radiation in Philips PW 3710 diffractometer to determine the abundance of the most common crystalline components of the investigated samples. The time of impulses counting in the step method was $3 \mathrm{~s}$ (per step), the counter speed was $0.01^{\circ}-0.02^{\circ}$ per minute, the lamp voltage $-45 \mathrm{kV}$ and the current intensity $-30 \mathrm{~mA}$. The estimated concentrations (\%) of the analyzed mineral components were given using the X'PERT computer program. 
${ }^{57} \mathrm{Fe}$ Mössbauer transmission spectra were recorded at room temperature by the use of a POLON type spectrometer and a linear arrangement of source ${ }^{57} \mathrm{Co}: \mathrm{Rh}$ $(\approx 15 \mathrm{mCi})$, a multichannel analyser, an absorber, and a detector. A gas proportional counter LND-45431 was used as a gamma-ray detector. The $2 \mathrm{keV}$ escape peak and $14.4 \mathrm{keV}$ gamma ray pulses were selected with a multichannel analyzer. The spectrometer was calibrated at room temperature with a $10 \mu \mathrm{m}$ thick $\alpha$-Fe foil. The numerical analysis of the Mössbauer spectra was performed by the use of the WMOSS program [5]. The mineralogical analysis of the spectra was based on the Mössbauer Handbook Mineral Data [6].

\section{Results and discussion}

The chemical composition of the investigated samples of dust and iron-bearing mud from filter press are shown in Table I. Chemical analysis indicated that the analyzed material contained a small amount of heavy metals: $\mathrm{Pb}$ (0.07-0.31 mass\%), Zn (0.02-4.08 mass\%), Cu (0.01-0.04 mass\%), Ti (0.02-0.17 mass\%) and others, accompanied by large amounts of Fe (13-54 mass\%). All the samples contained a significant amount of Ca (4-22 mass\%), especially in the samples from steelworks and de-dusting station. This element is the result of getting flux in smelting process of steel. In the samples of sintering dust from electrostatic precipitators one could observe high concentration of $\mathrm{B}$, which probably came from deducts process. The other elements completed the composition.

TABLE I

Elementary results (wt\%) found in investigated samples.

\begin{tabular}{c|c|c|c|c|c|c}
\hline \hline \multirow{2}{*}{ Element } & \multicolumn{7}{|c}{ Sample number } \\
\cline { 2 - 7 } & 1 & 2 & 3 & 4 & 5 & 6 \\
\hline $\mathrm{B}$ & 0.00 & 0.00 & 14.85 & 24.01 & 0.00 & 0.00 \\
$\mathrm{C}$ & 16.07 & 19.61 & 6.96 & 8.13 & 3.71 & 3.78 \\
$\mathrm{O}$ & 32.95 & 37.02 & 23.56 & 1.61 & 31.38 & 28.16 \\
$\mathrm{Na}$ & 0.73 & 0.26 & 2.92 & 7.83 & 0.46 & 0.00 \\
$\mathrm{Mg}$ & 1.63 & 3.17 & 0.51 & 0.23 & 0.65 & 0.75 \\
$\mathrm{Al}$ & 0.30 & 0.47 & 0.50 & 0.28 & 0.29 & 0.12 \\
$\mathrm{Si}$ & 1.12 & 1.81 & 2.32 & 1.47 & 1.59 & 1.08 \\
$\mathrm{~S}$ & 0.49 & 0.32 & 0.40 & 0.45 & 0.22 & 0.12 \\
$\mathrm{Cl}$ & 0.61 & 0.38 & 4.64 & 14.59 & 0.12 & 0.05 \\
$\mathrm{~K}$ & 0.42 & 0.16 & 2.21 & 7.99 & 0.11 & 0.08 \\
$\mathrm{Ca}$ & 11.14 & 21.83 & 5.79 & 4.21 & 7.03 & 6.43 \\
$\mathrm{Ti}$ & 0.04 & 0.17 & 0.02 & 0.02 & 0.02 & 0.03 \\
$\mathrm{Cr}$ & 0.03 & 0.04 & 0.02 & 0.02 & 0.04 & 0.09 \\
$\mathrm{Mn}$ & 1.00 & 0.48 & 0.06 & 0.06 & 0.75 & 0.72 \\
$\mathrm{Fe}$ & 28.51 & 12.61 & 35.05 & 28.34 & 49.62 & 54.15 \\
$\mathrm{Cu}$ & 0.01 & 0.02 & 0.01 & 0.04 & 0.05 & 0.03 \\
$\mathrm{Zn}$ & 2.83 & 1.00 & 0.02 & 0.04 & 3.63 & 4.08 \\
$\mathrm{~Pb}$ & 0.19 & 0.07 & 0.09 & 0.31 & 0.27 & 0.21
\end{tabular}

Phases obtained in the XRD analysis of the studied samples are summarized in Table II. As can be seen, all the samples contain spinel fraction (franklinite and/or
TABLE II

Minerals (wt\%) in the investigated dusts and ironbearing muds.

\begin{tabular}{l|c|c|c|c|c|c}
\hline \multirow{2}{*}{\multicolumn{1}{c|}{ Phase }} & \multicolumn{7}{|c}{ Sample number } \\
\cline { 2 - 7 } & 1 & 2 & 3 & 4 & 5 & 6 \\
\hline spinel & 19 & 9 & 38 & 20 & 10 & 6 \\
hematite & 27 & 0 & 5 & 38 & 23 & 24 \\
wüstite & - & - & - & - & 24 & 44 \\
$\alpha-$ Fe & - & - & - & - & 12 & 21 \\
calcite & 6 & 23 & 6 & 8 & 23 & 24 \\
sylvine & - & - & 6 & 27 & - & - \\
halite & - & - & 3 & 14 & - & - \\
graphite & 33 & 34 & - & - & - & - \\
periclase & 6 & 11 & - & - & - & - \\
portlandite & 4 & 9 & 1 & - & - & - \\
quartz & - & 3 & - & 5 & 2 & 3 \\
srebrodoloskite & 4 & 5 & - & - & 1 & 2
\end{tabular}

magnetite), calcite and a lot of hematite bating the sample 6. The dusts from steelworks and from de-dusting station include graphite, portlandite and periclase. Iron-bearing muds contain abundance of wústite and pure $\alpha$-Fe.

The Mössbauer spectra of all the investigated samples are presented in Fig. 1. All recognized Fe-bearing phases are visible on each spectrum together with their

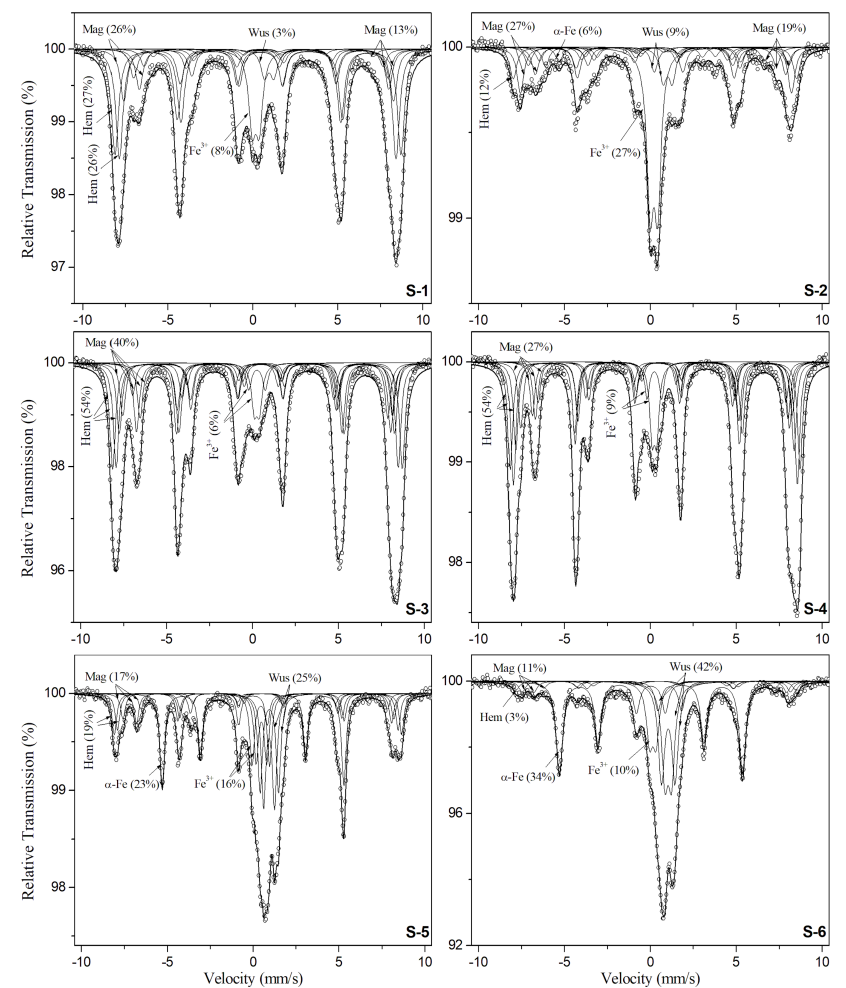

Fig. 1. Room temperature Mössbauer spectra and Mössbauer phases analysis of investigated dusts and iron-bearing muds: Hem — hematite, Mag — magnetite, Wus - wüstite. 
contribution (in the brackets). Small dispersion of hyperfine parameters observed especially for magnetite can be related to the fact that dust particles originating in steel production process take various morphological forms of different sizes.

The Mössbauer spectra obtained for dusts from the steelworks (S-1) and from the de-dusting station (S2) contain mainly magnetically ordered iron oxides like hematite $(51 \mathrm{~T}, 52 \mathrm{~T})$ and magnetite $(49 \mathrm{~T}, 46 \mathrm{~T}$ and $47 \mathrm{~T}, 45 \mathrm{~T}, 41 \mathrm{~T}$ ). For magnetite one could observe hyperfine magnetic fields with smaller values than these presented in literature, which can be the result of substitution of iron by another elements present in dust. These two samples contain a small part of iron located in nonmagnetic iron oxide like wüstite. Paramagnetic ferric doublet observed on these spectra with isomer shift of about $0.20 \mathrm{~mm} / \mathrm{s}$ and average quadrupole splitting of about $0.44 \mathrm{~mm} / \mathrm{s}$ probably corresponds to amorphous $\mathrm{Fe}^{3+}$ in glass, which was suggested by other authors [7-9].

On the Mössbauer spectra for dust from the sinter strand (samples 3 and 4) predominant components related to hematite and magnetite. Only a small amount of paramagnetic iron located in glass is visible.

Components connected with pure $\alpha$-Fe phase and wüstite dominated on the Mössbauer spectra of the samples connected with iron-bearing mud from the filter press (samples 5 and 6). Also, a small amount of magnetically ordered iron oxide (hematite and magnetite) is visible.

\section{Conclusions}

The techniques applied have proven to be useful in the investigation to better describe the modes of occurrence of Fe-bearing species in dusts generated during steel production.

Due to the changeable mineralization and their chemical composition, metallurgical slags are one of the most diverse groups of wastes. Chemical analysis indicated that the analyzed materials contained a large amount of $\mathrm{Fe}, \mathrm{C}, \mathrm{Ca}, \mathrm{B}$, and a very small amount of heavy metals: $\mathrm{Cd}, \mathrm{Pb}, \mathrm{Zn}, \mathrm{Cu}$, Ti. On the other hand, using modern solutions (electrofilter precipitators) prevents the release of dangerous, volatile elements to atmosphere.
The X-ray diffractograms of dust samples revealed that the dominant components were some spinels, hematite, calcite and portlandite. The Mössbauer measurements clearly identified the content of Fe-bearing phases and the oxidation state of iron. Wüstite, hematite, magnetite and pure iron dominated in the samples of dusts and muds - the Mössbauer spectra confirmed these results. The investigated samples of dusts contained mainly $\mathrm{Fe}^{3+}$ ions.

\section{Acknowledgments}

The research project received funding from the National Science Centre of Poland on the basis of the decision number DEC-2013/09/B/ST10/02227.

\section{References}

[1] A. Stefanova, J. Aromaa, A. Forsen, Physicochem. Probl. Miner. Process. 51, 293 (2015).

[2] Z. Huaiwei, H. Xin, Res. Con. Recycling 55, 745 (2011).

[3] M. Arshed, M. Siddique, M. Anwar-ul-Islam, A. Ashfaq, A. Shamim, N.M. Butt, Solid State Commun. 98, 427 (1996).

[4] I. Prisecaru, WMOSS4 Mössbauer Spectral Analysis Software, www.wmoss.org, 2009-2016.

[5] S. Virolainen, R. Salmimies, M. Hasan, A. Häkkinen, T. Sainio, Hydrometallurgy 140, 181 (2013).

[6] J. Stevens, A. Khasanov, J. Miller, H. Pollak, L. Zhe, Mössbauer Mineral Handbook, Mössbauer Effect Data Center, Asheville, USA 2005.

[7] Ch. Haihan, A. Laskin, J. Baltrusaitis, Ch. Gorski, M. Scherer, V. Grassian, Environ. Sci. Technol. 46, 2112 (2012).

[8] M. Oliweira, F. Waanders, L. Silva, A. Jasper, C. Sampaio, D. McHabe, R. Hatch, J. Hower, CCGP 3, 35 (2011).

[9] M. Kądziołka-Gaweł, D. Smolka-Danielowska, Nukleonika 62, 101 (2017). 